\title{
PLANOS DE VIDA E MANEJO DO MUNDO: COSMOPOLÍTICA INDÍGENA DO DESENVOLVIMENTO NA AMAZÔNIA COLOMBIANA
}

\author{
Luis Cayón - Universidade de Brasília
}

\section{INTRODUÇÃO}

$\mathrm{Na}$ Colômbia, os indígenas constituem uma minoria que é muito heterogênea. O censo de 2005 calculou a população indígena em quase um milhão e quatrocentas mil pessoas, que equivale apenas a 3,3\% da população total da nação. Atualmente, as instituições estatais reconhecem oficialmente a existência de 87 povos indígenas e de 65 línguas diferentes, cifras que demonstram a grande diversidade cultural do país. Os povos indígenas se distribuem por todas as regiões e a maior parte deles habita em Resguardos, terras reconhecidas legalmente pelo Estado, e que abrangem entre $25 \%$ e 29\% do território nacional. Mais da metade da população indígena vive na região andina, no Caribe e nos vales interandinos, enquanto aproximadamente $20 \%$ vive na Amazônia. No entanto, é na Amazônia que se encontra a maior diversidade cultural e étnica do país, representada por 62 povos (Jimeno 2012: 60). Pode parecer um paradoxo, mas a inegável presença indígena apenas se fez visível para o resto da nação há cerca de duas décadas.

Como uma praga contínua que se espalha da Colônia até o presente, atravessando todo o processo de construção da nação colombiana -iniciado em 1810 a partir da Declaração de Independência da Espanha-, os índios têm sofrido inúmeros abusos, como a usurpação das suas terras e assassinatos, porque sempre foram vistos pelas elites governantes como um empecilho para o progresso e desenvolvimento do país. O projeto de uma nação hispânica e católica composta de uma população homogênea, de caráter mestiço, considerou sempre os índios como "inferiores” e “selvagens" que deviam ser obrigados a “civilizar-se". Desde o final do século XIX e até a década de 1960, a legislação considerava que os "selvagens" reduzidos à vida civilizada passariam de um regime de propriedade coletiva das terras a outro de propriedade privada de modo a eliminar gradualmente os Resguardos. Aqueles que retardassem seu processo civilizatório, deveriam ficar sob a autoridade dos missionários, os quais os evangelizariam e lhes ensinariam o castelhano. Para os povos indígenas andinos que viviam mais perto das cidades e de outros núcleos urbanos e sendo a região andina o núcleo da construção da nação, as expropriações de terras por meios violentos ou enganosos praticadas pelas elites regionais, formadas por latifundiários e políticos, passaram a ser parte da vida cotidiana. Os povos indígenas das regiões mais longínquas, inclusive aquelas onde não chegavam os missionários, ficaram à mercê de colonos e comerciantes. Estes se aventuravam pela floresta em busca de fortuna na exploração da borracha ou de outros produtos, submetiam os índios pela força, como mão de obra semiescrava, e os violentavam permanentemente. Como resultado, vários povos foram exterminados, outros conseguiram sobreviver, mas terminaram subjugados e explorados por 
latifundiários, missionários e seringueiros, outros se desestruturaram e foram assimilados como camponeses, outros camuflaram-se entre a população regional e outros foram expulsos das suas terras e chegaram às cidades.

Segundo Jimeno (2012: 61-64), no começo da década de 1960, quando as ideias desenvolvimentistas enraizaram-se nas elites governantes, iniciou-se um processo de modernização que buscava combater o atraso social e econômico das áreas rurais. Por uma parte, isto permitiu a ampliação e constituição de novos Resguardos, em especial naAmazônia e nas terras da nação consideradas como baldias, e, por outra, contribuiu para o surgimento de movimentos camponeses e indígenas na região andina, abrindo espaço para que apresentassem suas reivindicações. Apoiados por intelectuais e ativistas, os movimentos indígenas transformaram-se em Conselhos Regionais Indígenas que foram se articulando para constituir organizações de nível nacional. Com o passar dos anos, o movimento político indígena foi se consolidando ao ganhar força política e visibilidade, iniciar uma interlocução direta com diferentes instituições estatais e começar a ocupar um espaço no imaginário nacional mediante suas ações e reivindicações políticas e culturais.

Em 1991, no contexto dos acordos de paz com vários grupos guerrilheiros, em especial o M-19, e com uma forte influência de conceitos neoliberais para a reforma da estrutura do Estado, redigiu-se uma nova Constituição Política que também incluiu as conquistas obtidas pelos movimentos indígenas após várias décadas de luta. Segundo a Constituição de 1991, a Colômbia se define como um país pluriétnico e multicultural que reconheceu os direitos territoriais e de cidadania plena dos índios, assim como a autonomia das suas formas de governo e de vida. Esta forte virada no processo de construção da nação trouxe desafios enormes para todos os atores sociais, gerando novas formas de relação entre os índios e os agentes do Estado, dificuldades e paradoxos; por exemplo, tanto a extrema direita como os grandes empresários questionam o fato de que uma porcentagem ínfima da população nacional possui quase 30\% das terras da nação, obstruindo o progresso do país, porque nessas terras concentra-se a maior parte das riquezas não exploradas. É evidente que as diversas instituições estatais não estavam preparadas para enfrentar todas as complexidades derivadas do reconhecimento da diversidade cultural do país, tornando mais nítidas as diferenças entre o que as autoridades estatais pensam sobre a administração da diversidade cultural e os modos como os indígenas exprimem suas múltiplas maneiras de viver e entender o mundo, que por si só já diferem das suas próprias práticas internas.

A partir da Constituição as instituições estatais formularam uma única legislação para amparar a diversidade cultural do país, gerando, assim, uma homogeneização fictícia de tal diversidade sob o manto do multiculturalismo. Por isso, vários intelectuais, nacionais e estrangeiros, que estudam o caso colombiano optaram por analisar as diferentes implicações políticas do multiculturalismo, suas contradições e paradoxos para lançar luzes sobre a situação contemporânea dos indígenas na Colômbia. Estes autores identificaram vários problemas derivados da legislação vigente, pois embora esta tenha sido um mecanismo eficiente para o reconhecimento das identidades étnicas (Gros 2000: 124), também pode ser entendida como uma nova forma de colonialismo (Jackson 1998: 306; Wade 2004: 264) em que as instituições do Estado criaram certos parâmetros para decidir a quais grupos étnicos reconhecem ou não direitos constitucionais. Estes parâmetros se sustentam no fato de possuírem uma cultura distintiva, um território e uma forma de governo específica (Chaves 2010: 197) que valorizam ideais associados a autenticidade, tradição, 
comunalidade (Restrepo 2011: 46), além de sabedoria ecológica, sistemas médicos próprios, etc. Assim, para os atores estatais, o modelo do outro é aquele do "nativo puro" que habita em serras e florestas distantes das cidades e conserva e fortalece uma cultura tradicional. Esta visão dos agentes do Estado criou ambiguidades e paradoxos nos quais os atores estatais têm demonstrado, para dizer o mínimo, sua morosidade: hoje, as instituições do Estado colombiano têm grandes dificuldades para reconhecer os direitos das alteridades que não se ajustam aos parâmetros culturalistas que elas mesmas criaram (Bocarejo e Restrepo 2011: 10), deixando em apuros, principalmente, os índios que vivem nas cidades (Chaves e Zambrano 2006: 13-14; Bocarejo 2011: 104-106) ou migraram para elas, ou aqueles que estão em processo de re-emergência étnica ou re-indigenização (Chaves e Zambrano 2006: 10). Isto significa que vários destes grupos devem mobilizar uma linguagem de indianidade para obter reconhecimento e legitimidade (Jackson e Ramírez 2009: 35), fato interpretado muitas vezes e por múltiplos atores como manipulação "mentirosa" e "oportunista" da identidade étnica. Desta forma, o multiculturalismo oficial na Colômbia aparece como uma arte de governo (Bocarejo e Restrepo 2011: 7-8) que determina quem pode ou não ser reconhecido como sujeito étnico. Esta situação está muito longe de ser exclusiva da Colômbia (por exemplo, ver Povinelli [2002] para a Austrália), pois o poder de criar, reconhecer e negar alteridades é característico dos Estados.

Ao criar assimetrias que não unicamente são políticas, mas também ontológicas e epistêmicas, o multiculturalismo oficial, atuando tanto no plano ideológico como através das práticas de vários atores estatais, pode entender-se como uma ontologia política hegemônica (Blaser 2009: 11) que distribui direitos, espaços e territórios às alteridades reconhecidas, enquanto nega a outras. Isto faz com que o mosaico geral da situação indígena na Colômbia apareça sob formas muito variadas e ambíguas, pois enquanto alguns povos lutam pelo reconhecimento étnico, outros discutem os alcances da sua autonomia territorial e política. Nesta direção, entendo que a relação atual entre o aparato estatal colombiano e os povos indígenas se fundamenta em uma assimetria de poder na qual os atores estatais tentam exercer um domínio ideológico e da prática política que é contestado, neutralizado e ressignificado pelos indígenas mediante diversas formas e estratégias.

Apesar dos inegáveis e, na maioria das vezes, desastrosos efeitos práticos que tal assimetria de poder produz para os índios, conceitualmente falando, ela é um artificio discursivo e prático que se apoia no caráter intimidador do Estado, advindo do seu monopólio legítimo da força, como sugere a clássica definição de Max Weber. Por isso, interessa-me analisar os encontros e desencontros entre atores do Estado e povos indígenas, partindo da premissa de que tanto as formações do Estado quanto as formas de existência e vida indígenas são construídas histórica, intelectual e fenomenologicamente a partir de conceitos múltiplos que, uma vez colocados na arena do diálogo interétnico, acabam se confrontando por meio de noções divergentes daquilo que nós traduzimos como natureza, cultura, humanidade, entre outros conceitos fundamentais a partir dos quais se constituem diversos mundos e formas de vida. Desta perspectiva, as construções elaboradas pelas autoridades estatais e pelos índios têm a possibilidade de se aproximar, embora cada uma constitua um mundo autônomo, ontologicamente autodeterminado, que pode se relacionar com qualquer outro por meio da tradução.

Conceitualmente, cada mundo particular é simétrico a qualquer outro, embora, na prática, quando algum deles 
se encontra com outro, as relações de poder entre eles são sempre assimétricas quando está presente algum agente do Estado. Nesses casos, estas alteridades são obrigadas a se adaptar e enfrentar as políticas multiculturalistas promovidas pelas instituições e atores estatais e, para isso, recorrem, entre outras coisas, aos seus próprios esquemas e regimes cosmológicos e políticos, podendo reafirmar, reajustar ou negociar algumas condições dos seus próprios mundos e tentar, assim, neutralizar as assimetrias de poder. Apesar de que os múltiplos mundos podem submeter-se a conflitos e tensões, em situações específicas podem se tornar inteligíveis e isso abre espaços de negociação direcionados à neutralização de tais assimetrias. Isabelle Stengers (2005: 995) criou o conceito de "cosmopolítica" para analisar as articulações que eventualmente os mundos múltiplos e divergentes são capazes de realizar, em vista de novos modos de coexistência possíveis, uma vez que esses mundos estão em pé de igualdade. Por isso, é importante refletir sobre as maneiras como esses mundos diferentes se encontram sem, necessariamente, convergir, tornando-se, ocasionalmente, inteligíveis.

Uma das vantagens de usar esta abordagem teórica é indagar sobre a multiplicidade de formas indígenas da prática política, e me parece de interesse especial enfocar as maneiras como diversas organizações indígenas usam e ressignificam conceitos cosmológicos para negociar suas realidades com os Estados, elaborar suas próprias traduções e compreensões sobre eles (Rappaport 2005: 94-98, 235-240) e, inclusive, criticá-los (Albert 2002: 251-252). Este enfoque permite pensar que o importante é tentar entender as maneiras como se busca inteligibilidade entre mundos diferentes. Nesta direção, este texto busca descrever e analisar o uso cosmopolítico que a Associação de Capitães Indígenas do rio Pirá-paraná(ACAIPI), daAmazônia colombiana, tem dado ao seu conceito de "calendário ecológico" para reivindicar e negociar sua forma particular de vida diante das políticas de desenvolvimento promovidas pelos agentes do Estado e como, ao mesmo tempo, esse conceito opera de modo diferente nas articulações políticas com organizações indígenas brasileiras, territorialmente vizinhas, para retroalimentar experiências diferentes e buscar pontos em comum para fortalecer suas alianças além da fronteira.

\section{AS ETI'S E O ORDENAMENTO TERRITORIAL INDÍGENA}

Desde os dias da Independência, a formação do Estado colombiano se caracteriza por uma tensão entre forças políticas regionais e outras que buscam centralizar o poder. Este embate político entre as elites já produziu inúmeros conflitos armados, exclusões sociais e problemas fundiários que se traduziram em um Estado fraco que ora de maneira deliberada, ora por inépcia ou por ambas ao mesmo tempo, não teve presença histórica -nem a tem hoje- em grande parte do território nacional e tampouco garantiu direitos a amplos segmentos da população. Essa ausência de instituições e agentes do Estado em muitos lugares do país tem contribuído para a intensificação do conflito atual-agravado pelo narcotráfico- entre guerrilhas esquerdistas, as forças legítimas do Estado (exército e polícia) e os paramilitares de extrema direita (apoiados sigilosamente por setores das forças militares e das elites políticas e econômicas), onde as forças irregulares têm exercido, à sua maneira, o papel que corresponderia ao Estado. Como nos séculos passados, os índios, outras minorias e os camponeses continuam sendo vítimas das ações violentas dos atores armados. As questões relacionadas com o controle e os direitos ao território constituem o nó górdio do conflito armado colombiano. 
A Constituição de 1991 outorgou o caráter de cidadãos aos índios, com igualdade de direitos e deveres, e reconheceu-lhes uma série de direitos coletivos. Dentre estes, quero destacar apenas o direito à propriedade territorial. AConstituição reafirma que os Resguardos são propriedade coletiva e inalienável, são inembargáveis e imprescritíveis. Dentro desses territórios reconhece-se a jurisdição das autoridades indígenas em tudo que está relacionado ao uso do solo, proteção ambiental, povoamento, elaboração de planos de desenvolvimento econômico e social, aplicação de recursos, entre outros. Se algum agente externo quiser explorar recursos naturais dentro dos Resguardos, deve pedir autorização às autoridades indígenas e a exploração econômica não se pode dar em detrimento da integridade cultural (Jimeno 2012: 67-69). Também, e fundamental da perspectiva da autonomia, os Resguardos e suas autoridades podem constituir Entidades Territoriais Indígenas (ETI's). ETI é uma figura político-administrativa que reconhece aos índios o governo dos seus territórios por meio das suas autoridades tradicionais e permite "definir jurisdições territoriais equiparáveis às entidades existentes -municípios ou departamentos-, de modo que posam gozar de plena autonomia na gestão dos seus interesses" (Rivera e Gómez 2006: 254), recebendo recursos econômicos chamados de transferências, que são royalties da nação destinadas para seu funcionamento. Entre outras implicações, as ETI's devem se integrar como novas formas organizativas da nação e às autoridades indígenas seriam transferidas funções estatais de controle territorial. Devido a inúmeros conflitos políticos e burocráticos provocados por questões relativas ao novo ordenamento territorial e às implicações que as ETI's podem ter para os poderes regionais, esta lei foi aprovada pelo Congresso da República apenas em meados de 2011, 20 anos depois de promulgada a Constituição, mas continua sem regulamentação. Por enquanto, as ETI's só existem no papel e não se concretizam porque a sua implementação afetaria poderosos interesses políticos e econômicos, não só das elites regionais, mas também dos atores armados ilegais.

Contudo, isto nãoéum obstáculo para que as organizações indígenas avancemna concretização dos seus direitos constitucionais. Como a implementação das ETI's implica processos organizativos e de reordenamento territorial, assim como a transferência de recursos econômicos do Estado, muitos povos indígenas da Amazônia colombiana começaram se organizar em Associações de Autoridades Tradicionais Indígenas (AATI's) desde a década de 1990. Estas Associações são de caráter público e contam com uma jurisdição territorial definida, tornando-se os antecedentes políticos e organizativos mais importantes das ETI's (Rivera e Gómez 2006: 254), e atualmente, são o centro dos processos de negociação com os agentes do Estado. Para levar adiante suas reivindicações, as AATI's elaboraram, como quesitos prévios para a implementação das ETI's, Planos de Ordenamento Territorial, também conhecidos como Planos de Vida. Estes se entendem como "Planos de Desenvolvimento Integral ajustados às características de cada povo indígena, e que devem ser adotados por seus membros. Este Plano de Desenvolvimento contempla os aspectos econômicos, sociais, ambientais, geográficos e políticos, conforme os usos, costumes e cosmovisões de cada povo" (Rivera e Gómez 2006: 256).

No entanto, a conformação das ETI's estará sujeita às disposições da Lei Orgânica de Ordenamento Territorial. Assim, as autoridades indígenas devem elaborarnos seus territórios as políticas, planos e programas de desenvolvimento econômico e social “em harmonia com o Plano Nacional de Desenvolvimento" (Rojas 2002: 341). Isto implica que, 
para o aparato estatal, as ETI's fazem parte das políticas de descentralização e redução do Estado enquadradas no neoliberalismo, políticas que buscam privilegiar as potencialidades econômicas das regiões e a sua auto-sustentação, de modo a aliviar o peso do Estado central. Esta é uma tendência mundial que pretende identificar as vantagens comparativas de uma região para que possa conquistar mercados dentro de uma economia globalizada (Vieco 2000: 221). Por esta razão, o ordenamento territorial indígena faz parte do Plano de Desenvolvimento da Nação, e sob essa óptica, os agentes estatais pretendem que os índios façam um inventário dos recursos naturais dos seus territórios para ver as potencialidades produtivas que, no futuro, os próprios índios, quando tenham suas ETI's, terão que gerenciar nas suas terras, de modo a obter recursos para projetos de desenvolvimento, saúde e educação, entre outros.

Oprocesso de ordenamento territorial éuma dinâmica queenvolve todaa Naçãoe nãoé exclusivo dos territórios indígenas, já que também inclui os municípios e departamentos. De fato, as instituições estatais supõem que, antes das ETI's entrarem em vigor, o ordenamento territorial indígena deve estar incluído no Plano de Desenvolvimento do município em que está adstrito um Resguardo. Na perspectiva dessas instituições, o ordenamento territorial indígena é um Plano de Desenvolvimento, que deve ser entregue ao Departamento Nacional de Planejamento, mas chega com o nome de Plano de Vida. Além do inventário de recursos, também contém as expectativas sobre o futuro de cada povo indígena. Em grande medida, os direitos reconhecidos aos índios estão associados à ideia de uma correlação efetiva entre biodiversidade, conservação da natureza e territórios indígenas, no contexto da crise ambiental global que encontra no desenvolvimento sustentável sua única saída, e por isso é importante a proteção e autonomia dos indígenas e dos seus territórios, pois, na visão estatal colombiana, não se trata exatamente de remediar assimetrias históricas, mas de ter algum controle sobre os recursos de terras onde o Estado nunca teve uma presença efetiva. Com isso também tentam reconhecer os direitos de cidadania dos índios, incluindo-os em um modelo geral de desenvolvimento, entendido pelos agentes do Estado como produção e exploração de recursos para melhorar as condições de vida da população pelo acesso a serviços públicos. Então, os princípios de igualdade e justiça presentes na Constituição colombiana, como em qualquer sociedade democrática e capitalista, supõem certa igualdade no acesso a serviços materiais e ao mercado. Porém, enquanto a descentralização não se realiza, as instituições estatais devem colaborar com os serviços para os povos indígenas até que estes tenham a capacidade de gerar seus próprios recursos e satisfazer suas demandas materiais (educação, saúde, projetos produtivos, etc.). Assim, as expectativas dos atores estatais frente aos Planos de Vida têm mais a ver com o fato de os índios conseguirem estabelecer alianças futuras para garantir seu próprio desenvolvimento, diminuindo as responsabilidades do Estado para com eles, do que incluí-los efetivamente como cidadãos plenos.

Neste sentido, as contradições geradas pelas políticas estatais com relação aos índios são evidentes, já que, de um lado, se diz buscar a preservação da autonomia indígena mediante a transferência de funções estatais de controle territorial, e ao mesmo tempo, de outro, tenta-se integrar os índios como cidadãos mediante o desenvolvimento. Ou seja, os indígenas devem procurar os meios para obter seu próprio desenvolvimento para "melhorar suas condições de vida", ou, dito de outra forma, a única maneira de os índios alcançarem seus direitos como cidadãos colombianos é entregar-se aos braços do desenvolvimento e da autogestão. Portanto, os agentes do Estado concebem o ordenamento territorial indígena como um modo de incorporação dos índios à nação, tratando de lhes impor seu projeto próprio. 
No entanto, as organizações indígenas do país perceberam nestas contradições das políticas estatais um espaço de negociação onde o ordenamento territorial surge como uma oportunidade de consolidar sua autonomia ou de recuperar seus espaços tradicionais (Franky 2001: 75) e começaram a trabalhar nos seus Planos de Vida a partir da perspectiva das suas trajetórias históricas particulares para validar suas "culturas" e formas de vida perante os agentes estatais. Dessa maneira, os Planos de Vida adquiriram um caráter cosmopolítico, pois, da perspectiva indígena, implicam uma tentativa de articular suas realidades frente às instituições do Estado, depois de refletir durante anos sobre o que estas querem, e espera-se que elas validem os Planos para que os indígenas exerçam sua autonomia.

\section{O PLANO DE VIDA DOS POVOS INDÍGENAS DO RIO PIRÁ-PARANÁ}

O Pirá-paraná é um rio de águas negras que flui de norte a sul até desembocar no rio Apaporis, conectando por diferentes caminhos terrestres e fluviais a bacia dos rios Uaupés e Negro com a dos rios Apaporis e Caquetá/Japurá. O Pirá está localizado no Departamento do Vaupés, na Colômbia, relativamente perto da fronteira brasileira, aonde se pode chegar das cabeceiras de alguns dos afluentes orientais. Neste rio habitam os povos Makuna, Yuhup-makú, Tatuyo, Barasana, Bará, Taiwano e Karapana (ACAIPI 2008: 1). Com exceção dos Yuhup, todos os outros povos pertencem à família linguística Tukano oriental. A população é de aproximadamente 1400 habitantes que vivem em 13 aldeias ou comunidades e em 39 malocas vizinhas. Este território indígena ocupa cerca de $5400 \mathrm{~km} 2$ que pertencem ao Grande Resguardo do Vaupés (ACAIPI 2008: 1) e está sob a jurisdição da Associação de Capitães Indígenas do Pirá-paraná (ACAIPI), AATI criada em 1995.

Os povos indígenas doPirá-paraná fazem parte do complexo sociocultural do NoroesteAmazônico, um enorme sistema de integração regional que inclui ao redor de 30 povos indígenas falantes de línguas tukano orientais, aruaque, caribe e makú-puinave, articulados por redes de troca matrimonial, de objetos rituais e de cultura material. Os povos atuais se estruturaram a partir dos sobreviventes de um longo e trágico processo histórico de contato com as sociedades coloniais que, apesar de causar uma forte queda demográfica, não conseguiu extinguir os índios nem sua forma de vida. De fato, a etnologia tem prestado muita atenção a esses povos, pois partilham certas características que os fazem únicos no contexto das terras baixas sul-americanas, como, por exemplo, seu multilinguismo, sua organização social (unidades exogâmicas patrilineares e segmentares ordenadas hierarquicamente, residência patri/virilocal, exogamia linguística, etc.) e a celebração do ritual do jurupari, cerimônia com flautas que evoca a força criativa do universo e que opera a transformação dos jovens em adultos.

Os povos indígenas do Pirá-paraná partilham uma origem comum, relacionam-se entre si como irmãos mais velhos e irmãos mais novos e se reconhecem como descendentes de um grupo de sucuris ancestrais aparentadas por consanguinidade, ou como cunhados que se originam de conjuntos de sucuris ancestrais diferentes. As autoridades tradicionais são os especialistas rituais (donos de maloca, xamãs ou kumua, cantores-dançarinos) e os capitães (autoridades administrativas) de cada aldeia, e todos eles fazem reuniões periódicas convocadas por ACAIPI para discutir, refletir e tomar decisões conjuntas sobre diversos temas, como o manejo coordenado do território com as flautas de jurupari, os Planos de vida, o uso de royalties, a educação, a saúde, etc. Os representantes legais daAssociação, 
geralmente, são homens adultos com um conhecimento melhor do castelhano e com mais experiência de interação com os brancos, pois devem assistir a reuniões em diferentes cidades da Colômbia e, às vezes, no exterior, para depois informar e analisar, junto com as autoridades tradicionais, os diferentes processos políticos que estão em andamento. Nessas reuniões, as vozes e opiniões dos kumua mais prestigiosos, donos do conhecimento erudito, são ouvidas com muita atenção.

Essa forma de trabalho e de tomada de decisões é, em parte, inovadora na região, pois, sem eliminar conflitos e disputas, combina a autonomia de cada povo com a criação de um consenso entre todos os povos do rio para o funcionamento adequado da Associação. É certo que, anteriormente, cada povo ou algum dos seus segmentos tomava decisões individualmente e buscava alianças segundo as propostas de um dono de maloca ou de um kumu (singular de kumua) - por exemplo, atacar uma maloca de outro grupo para roubar mulheres, enfeites rituais ou provocar uma guerra (Cayón 2003: 92-93). Mas também se supunha que o kumu principal de cada grupo fazia os trabalhos de fertilização exclusiva do próprio território por meio das flautas de jurupari, sem interferir nos territórios vizinhos (o que seria interpretado como um ataque por feitiçaria e poderia provocar uma guerra). Dessa forma, com cada kumu dedicado a fertilizar o território do seu grupo, promovia-se o bom viver e o funcionamento adequado de toda a bacia do Pirá-paraná. Segundo suas narrativas, estes povos presumem ter uma origem comum resultante dos percursos que fizeram as sucuris ancestrais de cada povo, desde os confins do universo, para povoar os territórios atuais. Cada povo possui um território particular, em geral, algum dos afluentes importantes do Pirá, que foi entregue pelos demiurgos nos tempos da criação do mundo, junto com uma língua distintiva, um conjunto de flautas de jurupari e de enfeites rituais para que cada povo tivesse o poder e o conhecimento de manejar seu território graças ao trabalho dos kumua. Esse manejo implica usar as flautas de jurupari durante um ritual, no começo da época das chuvas, para ativar a força criativa do universo contida nas flautas, e com ela gerar a vitalidade de todos os seres não humanos, garantir a sucessão ordenada das estações, evitar a erosão das margens do rio, impedir o surgimento de doenças, entre outras coisas (Cayón 2002: 146-152). Os kumua ativam a força criativa do jurupari e se encarregam de fazê-la chegar às malocas dos não humanos por meio das suas recitações e sopros sobre rapé de tabaco e coca para que se reproduzam. Assim, o manejo que cada povo faz do seu território próprio articula-se com os dos outros povos dos rios Pirá-paraná e Apaporis, para realizar conjuntamente o que eles traduzem como "manejo do mundo", ou seja, permitir que os processos vitais dos diversos seres e a sucessão das estações se realizem sem inconvenientes em uma escala maior que inclui os rios Piráparaná e Apaporis com seus afluentes. Nesse sentido, uma das novidades que a Associação trouxe é a de permitir que as autoridades tradicionais se encontrem face a face, conversem e tomem decisões conjuntas, ao mesmo tempo em que têm um espaço público de reflexão sobre os assuntos interétnicos.

Um dos resultados mais importantes desta forma de trabalho foi a elaboração do Plano de Vida para o Piráparaná, finalizado em 2008. É preciso esclarecer que eu não fiz parte desse processo de elaboração, pois meu papel tem sido mais o de observador distante, porém, durante minhas pesquisas de campo na região, que incluem um trabalho colaborativo e de serviço para eles segundo as necessidades do momento (elaboração de mapas ou planos de manejo ambiental, por exemplo), converso muito sobre estes temas e sou consultado para dar minhas opiniões sobre esses 
assuntos. AACAIPI, com assessoria da Fundação Gaia-Amazonas, trabalhou durante anos para formular a proposta de Plano deVida. Durante esse tempo, cada povo organizou grupos de trabalhoem cadaaldeia, contando com a colaboração dos kumua para elaborar os mapas dos seus territórios, identificando os percursos de cada sucuri ancestral ao trazer o grupo de descendentes a este mundo. Com isso, definiam com clareza os limites territoriais, os "lugares com nome" (também chamados "lugares sagrados") e suas histórias relacionadas. Cada kumu principal descreveu o percurso da sucuri ancestral do seu povo, pois os kumua são os detentores desse conhecimento exclusivo, a partir das recitações que aprenderam durante sua formação, do aprendizado visual sobre o mesmo tema produzido pela ayahuasca, e das visitas que fazem àqueles lugares com seu Pensamento em todo tipo de curas (Århem 1998: 94-99; Cayón 2010: 210-226). À medida que cada kumu falava, os professores e outros ajudantes desenhavam os mapas e depois os assessores da Fundação Gaia levavam esses mapas para ser digitalizados em Bogotá. Com esta forma de trabalho, os índios também elaboraram "calendários ecológicos culturais" onde sintetizaram e representaram graficamente seu conhecimento sobre as características das estações e sua sucessão ordenada, juntamente com as atividades culturais praticadas em cada uma, o que até então era domínio exclusivo dos kumua e que era explanado eventualmente nas malocas por meio das formas narrativas que condensam o conhecimento erudito (ketioka). Os calendários ecológicos buscam subsidiar um Plano de Manejo Ambiental de todo o território para fortalecer a transmissão de conhecimentos tradicionais; ao mesmo tempo, contribuíram para unificar um sistema de escrita para as línguas da região. Após levantar toda esta informação e realizar inúmeras reuniões, chegou-se ao consenso que resultou no Plano de Vida apresentado ao Estado colombiano. É importante destacar que o processo de elaboração do Plano de Vida foi longo, pois, nos primeiros momentos, os assessores da Fundação Gaia tiveram muitas reuniões para discutir que metodologias seguir, e convencer as pessoas da necessidade de fazer os mapas do território, além de lhes ensinar algumas bases de conhecimento cartográfico para que pudessem descobrir a maneira de representar no papel o conhecimento contido nas narrativas dos kumua.

O Plano de Vida dos indígenas do Pirá-paraná está dividido em quatro partes principais: uma introdução onde declaram seus propósitos; a descrição das categorias de zoneamento ecológico da região; a descrição do território e o seu manejo ambiental, incluindo um diagnóstico dos conflitos e problemas atuais, e uma apresentação dos seus objetivos e estratégias para resolvê-los. Na introdução, os índios afirmam que a proposta "tem suas raízes no próprio plano de vida tradicional ou calendário ecológico cultural. Para nós, nosso plano de vida é o mesmo plano de ordenamento do nosso território, pois desde que os Ayawa, nossos deuses, criaram este mundo, o fizeram em uma ordem dada desde o nascimento, entregue em formas e saberes aos seres humanos" (ACAIPI 2008: 1); assim, cada grupo recebeu um território e sua forma de manejo, que existe até hoje. Afirmam que, devido ao contato com os não indígenas, as mudanças introduzidas na educação das crianças e o enfraquecimento de algumas curas dos kumua (termo que, ao longo do seu texto, eles traduzem indistintamente como xamã, curador, pensador e sábio), precisam de uma ordem e da criação de um novo caminho para que eles e seus descendentes possam ter um convívio pacífico e equitativo com todos os seres humanos. Tal caminho constrói-se a partir do ordenamento territorial que "nos oferece a possibilidade de entender, mostrar e levar a nós mesmos e aos outros aquilo que significa nosso plano de vida" para "encontrar respostas claras a respeito do que foi, é e será nossa forma de viver, usando os espaços que a lei colombiana abriu”, pois, com isso, "desejamos dar a conhecer a nossa situação, quanto ao manejo ambiental, saúde, educação, desenvolvimento 
socioeconômico e governo próprio, setores que conformam nossa proposta de ordenamento" (ACAIPI 2008: 2).

A seguir, o Plano de Vida faz uma descrição da estrutura geológica e dos tipos de vegetação na linguagem especializada da geologia, da botânica e da ecologia. Depois apresenta as categorias de zoneamento ecológico de acordo com as categorias "espaços de assentamento humano" (aldeias, malocas, casas de chão, escolas, postos de saúde, caminhos, roças, etc.), "espaços naturais de coleta de produtos da floresta para subsistência" (floresta de terra firme, savanas, aglomerados de palmeiras, etc.), "espaços de caça e pesca para subsistência" (terrenos salitrosos, lagoas, etc.), "espaços de conservação ou solos de proteção" (morros, cachoeiras, lugares sagrados, etc.). Cada uma das categorias conta com uma descrição sucinta das suas características, misturando termos ecológicos e tipificações nativas, explicando, para alguns, os usos diferenciados segundo as épocas de seca e de chuva, ou as restrições de uso.A parte do zoneamento ecológico conclui acoplando as categorias anteriores na definição de áreas florestais que constam no Código Nacional de Recursos Naturais: área florestal produtora, área florestal produtora protetora, e área florestal protetora. Na primeira, incluem-se as áreas de assentamento e cultivo, na segunda, os espaços de coleta, caça e pesca, e, na última, os lugares sagrados. Esta parte do Plano de Vida é produto de coautoria com os assessores da Fundação Gaia, os quais fizeram ajustes e traduziram certos aspectos para uma linguagem compreensível às instituições do Estado, embora isto nunca tenha sido explicitado no texto.

Mais adiante, afirmam que seu conceito de território inclui todos os seres, viventes ou não, os lugares sagrados, a distribuição dos grupos étnicos e as tradições culturais nas quais se incorporam dimensões sociais, políticas, econômicas, ambientais, educativas, saúde e manejo do território. Tudo isso "baseados no nosso conhecimento tradicional, que tem seus alicerces nos nossos calendários ecológicos culturais, que não são outra coisa se não nossos planos de vida" (ACAIPI 2008: 11). Reafirmam que seu território está ordenado desde que os demiurgos Ayawa lhes entregaram e que a forma de administrá-lo deriva do conhecimento de "manejar o mundo a partir de outra dimensão para obter assim o bem-estar da natureza e da humanidade... Todo esse conhecimento tem como base os calendários ecológicos culturais, que são o espelho dos lugares da natureza. A cada época do ano corresponde uma série de atividades produtivas, rituais, cuidados e curas que nos permitem regular a relação entre os seres humanos e a natureza" (ACAIPI 2008: 12). Continuando, explicam que os lugares sagrados têm donos sobrenaturais com os quais os kumua se comunicam, e que a boa comunicação entre eles mantém a ordem dentro do território. Se se falta com o respeito aos donos e lugares, surgem doenças e problemas e, por isso, eles se opõem totalmente a qualquer tipo de exploração mineira no seu território.

Tomando como exemplo os danos produzidos pela exploração de ouro no rio Traíra, nos limites do território, e que se iniciou no final dos anos 1980, eles criticam a destruição de alguns morros fundamentais para o bem-estar do território e examinam o processo histórico do contato. Seguindo a ordem dos booms extrativistas (borracha, coca, ouro), os índios explicam que, por causa da opressão que sofreram dos seringueiros, os xamãs tradicionais ou kumua não conseguiam manejar o mundo, porque eram forçados a trabalhar na extração do látex, e isso dificultou a transmissão do conhecimento. Além disso, a violência sofrida obrigou seus avós a se esconder na mata para se proteger, mas, logo 
depois, chegaram os missionários que, em nome da "civilização", induziram-nos a viver junto e formar aldeias. Com o passar do tempo e de outros booms, nos últimos anos, o fato de viver em aldeias tem produzido vários problemas, como: escassez de alimentos e de terras aptas para o cultivo, separação por muito tempo de pais e filhos que vão para as escolas e internatos -ficando estes últimos sem chance de aprender parte do conhecimento tradicional-, e o abandono gradual de algumas práticas rituais e de cuidado do corpo para manejar o mundo. Por estes motivos, os objetivos e estratégias do Plano de Vida para remediar estes problemas incluem executar todas as atividades seguindo o calendário ecológico cultural, fortalecer a cultura, estabelecer acordos com outras organizações indígenas vizinhas para o manejo apropriado dos territórios, incentivar os kumua a desempenhar todos os rituais e curas nos momentos adequados, fazer com que todos os habitantes ajustem suas atividades ao calendário ecológico cultural, estabelecer um sistema educativo que permita que as crianças fiquem perto dos seus pais para aprender as técnicas tradicionais, entre muitos outros. Eles afirmam que devem "trabalhar com os habitantes das comunidades e os xamãs para que as atividades de todos se ajustem ao calendário ecológico cultural de modo que se faça um manejo mais adequado dos recursos naturais segundo as estações, cumprindo com os cuidados para a prevenção de doenças, curas e rituais próprios das nossas culturas" (ACAIPI 2008: 18).

\section{CALENDÁRIOS ECOLÓGICOS}

O uso que a ACAIPI faz do seu "calendário ecológico cultural" no Plano de Vida está dirigido à busca de inteligibilidade com as instituições e agentes estatais. Com este conceito, os índios estão mostrando uma expansão da sua concepção própria da política ao tratar com esses agentes, e, por conseguinte, com o aparato estatal, que eles denominam “governo.” Essa concepção se soma a um complexo tecido de relações e níveis de operação política, no qual se incluem relações e negociações internas com os povos vizinhos (articulações rituais e de trocas matrimonias e de bens) e com lugares, espíritos, plantas e animais por meio das trocas de vitalidade (üsi oka) que realizam os kumua com os não humanos para reproduzi-los (ver Cayón 2010: 328-386). Aliás, com este conceito, os índios enfatizam que a base da política se enraíza no seu sistema de conhecimento e reivindicam sua forma de vida. Então, o que os indígenas do Pirá-paraná querem dizer com “calendário ecológico cultural” e do que trata esse sistema de conhecimento?

Os Makuna usam o termo rodori wanore (cura das estações) para se referir aos trabalhos realizados pelos kumua durante os basa (bailes ou rituais de cura) feitos na transição de uma estação para outra, assegurando que se cumpra rodori gaye, que podemos traduzir como "o próprio ou aquilo constitutivo das estações" e que faz referência ao conjunto cíclico formado pelas estações sucessivas, algo próximo da nossa ideia de "ano" e que eles traduzem hoje como “calendário ecológico". Em um primeiro nível, faz referência a todos os fenômenos relativos à sucessão cíclica do tempo na floresta: temporadas de verão e inverno (Århem 1981: 70), alternâncias nas constelações, oscilações no nível dos rios, piracemas, floração e frutificação de frutas silvestres e cultivadas, temporadas de acasalamento dos animais, chegada de aves migratórias, etc. O sistema de conhecimento dos índios do Pirá-paraná descreve em detalhe estes fenômenos que, nos nossos termos, definiríamos como ecológicos, e faz associações muito complexas sobre a articulação e simultaneidade de processos que nos pareceriam díspares. Por exemplo, eles sabem que depois da frutificação da pupunha (Bactris gasipaes), quando as Plêiades se aproximam do zênite, se produz uma última piracema 
que indica o começo da estação das chuvas, cujo momento inicial faz com que as rãs comestíveis üma cantem durante uma noite inteira, o que anuncia que as frutas silvestres estão prontas para ser coletadas e que os humanos podem planejar alguma das suas cerimônias com as flautas de jurupari. Todos esses conhecimentos "ecológicos", junto aos saberes minuciosos que têm sobre os lugares e os seres não humanos (comportamento, relações simbióticas, hábitos reprodutivos, alimentação, etc.) estão codificados nas fórmulas poéticas próprias da linguagem erudita dos kumua. Essa linguagem especial denomina-se ketioka, que pode traduzir-se parcialmente com a palavra Pensamento, e a ACAIPI nomeou todo seu sistema de conhecimento de "hee yaia keti oka" (Conhecimento tradicional dos xamãs-jaguares de jurupari), o qual foi reconhecido pela UNESCO (s.d.), em 2011, como herança cultural intangível da humanidade.

Em um nível mais profundo, aquilo que os índios do Pirá-paraná traduzem por “calendário ecológico" é conceitualizado como a forma de ser do mundo, seu temperamento, sua maneira particular de funcionar e agir. Esta “forma de ser" deriva-se dos cantos do jurupari primordial, o ser primevo, cujo corpo e voz possibilitaram a criação do espaço e do tempo, pois ele cantava como cigarra na época da cigarra, como rã na época das rãs, como as flautas de jurupari na época do jurupari(Cayón 2010:230-245). Ou seja, a “forma de ser”' do mundo implica a interrelação entre a sucessão do tempo e as mudanças nas características da floresta. Por exemplo, quando as cigarras cantam, começa uma temporada de verão em que caem as folhas das árvores e proliferam algumas lagartas comestíveis das quais se originam borboletas, tempo adequado para derrubar árvores para uma nova roça, para realizar o "baile de ovos de lagarta” e para construir objetos de madeira, como banquinhos e bastões rítmicos. Essa “forma de ser" influi no comportamento de todos os seres que povoam o mundo, pois os impregna das características da estação, podendo gerar doenças típicas ou abundância de certos alimentos (Cayón 2010: 245), e também determina as atividades humanas e as práticas sociais, já que indica onde e quando se pode semear, plantar, caçar, pescar, coletar, fazer rituais, abster-se ou não de sexo ou de certos alimentos, usar uma ou outra técnica culinária, seguir certas práticas de cuidado do corpo para prevenir doenças, fabricar determinados objetos e até visitar parentes que vivem em outras localidades (Cayón 2010: 168). Desta maneira, rodori gaye marca as dinâmicas da vida social, os parâmetros das diferentes faces da sua socialidade, define a morfologia social, o ciclo ritual, as atividades cotidianas apropriadas para cada estação, as permissões e proibições alimentares e, por isso, também estipula as formas de interação com os não humanos, por exemplo, se é permitido ou não caçar certo animal em um momento determinado.

A sequência completa do ciclo é possível, segundo eles, pelo trabalho dos kumua que garantem as transições entre estações por meio de rituais públicos periódicos nas malocas. Neles, enquanto o kumu faz silenciosamente uma cura chamada rodori wanore (cura das estações) soprando em substâncias como rapé de tabaco, coca, pintura preta, cera de abelhas e pimenta para dar vitalidade e proteção a crianças, mulheres e homens, inclusive aos não humanos -para atravessar a estação que chega sem problemas e doenças-, as outras pessoas cantam, dançam e, eventualmente, tomam bebidas fermentadas para se divertir e alegrar os outros habitantes do mundo. Há, inclusive, uma cura mais ampla chamada de ümüari wanore (cura do mundo) realizada durante as festas do jurupari no começo do ciclo, onde o kumu programa antecipadamente a sucessão das estações durante um ou vários anos, pois, manipulando a força criativa do jurupari, calibra os ritmos de reprodução nas malocas dos não humanos. As curas rodori wanore são também 
uma forma de reforçar esse planejamento. A cura do mundo realizada com as flautas de jurupari é a base de todo o "manejo do mundo" no Pirá-paraná e nos territórios vizinhos (Cayón 2010: 379-386). Podemos entendê-la como um ato de política cósmica, onde o kumu reafirma e reconstrói o tecido das relações sociais entre os humanos e os outros habitantes do mundo. Em suma, viver de acordo com o estipulado por rodori gaye, traduzido como calendário ecológico, é, literalmente, ordenar o território, "manejar o mundo" e seguir seu plano de vida, como bem afirmam na sua proposta.

\section{A BUSCA DA INTELIGIBILIDADE}

Não é necessário entrar em todos os detalhes e implicações da classificação nativa das estações nem do sistema de conhecimento do Pirá-paraná para entender que o Plano de Vida é, principalmente, uma proposta para articular realidades diferentes, cuja realização tem envolvido os índios em longas reflexões e discussões frente às demandas das instituições e agentes do Estado colombiano. Ao traduzir um dos seus conceitos cosmológicos principais para buscar inteligibilidade entre ambos os mundos, alternando o uso de uma linguagem técnica da geologia e da ecologia para descrever sua região com os elementos da sua própria realidade, eles fazem do Plano de Vida uma cosmopolítica. Por um lado, cumprem o que os agentes estatais querem, mapeiam seus territórios e localizam seus recursos para que os atores do Estado tenham uma ideia do que neles existe, e, por outro, reafirmam sua forma de vida para o futuro, seu "plano de desenvolvimento", percebendo nos processos de diálogo para construir o Plano de Vida um mecanismo para resolver problemas que os preocupam e reforçar seu sistema de conhecimentos. Assim, o Plano de Vida e o calendário ecológico não são apenas uma tentativa de articulação política com as instituições estatais, mas também se transformaram em uma forma de política interna e externa, que se contrai e expande segundo as necessidades, um mecanismo eficiente para se articular com outras organizações indígenas e um meio de fortalecer seu peso político. Como bem apontou Albert (2002: 242), "se o discurso político indígena se limitar à mera reprodução das categorias brancas, ele se reduzirá a uma retórica oca; se, por outro lado, ele permanecer no âmbito exclusivo da cosmologia, não escapará do solipsismo cultural", então é a capacidade de articular estes dois planos que garante o seu sucesso.

Este Plano de Vida apresenta semelhanças com outras propostas de ordenamento territorial de três AATI's da Amazônia colombiana, próximas à jurisdição da ACAIPI, e que já foram analisadas alhures (Cayón e Turbay 2005: 100-110; Cayón 2009: 212-217). Embora cada proposta mobilize politicamente conceitos cosmológicos distintos, mas relacionados com uma ideia ampla de "manejo do mundo", vale a pena ressaltar vários pontos em comum: os quatro Planos de Vida estruturam-se a partir dos temas de ordenamento territorial, saúde, educação, desenvolvimento socioeconômico e governo próprio. Sempre usam traduções de certos conceitos fundamentais centrados nas atividades de geração de vitalidade realizados pelos kumua para cumprir uma função política tendo em vista o mundo exterior. Nas quatro propostas, os índios mostram-se a si mesmos como povos que já têm seus territórios ordenados e governos próprios desde a origem dos tempos. Embora não tenham um conceito de "natureza", já que seu mundo está construído em termos sociais (Cayón 2010: 191), os índios adotam este conceito dentro dos seus Planos de Vida e relacionam-no com os "lugares com nome" ou "sítios sagrados", como os traduzem em espanhol. De qualquer maneira, o uso que 
fazem do conceito "natureza" é diferente do ocidental, pois para eles não primam as visões de exploração de recursos nem de acumulação de riqueza, mas a existência de elos sociais entre os humanos e os outros seres, fundamentados em trocas e respeito mútuo, aspecto sempre ressaltado nos Planos de Vida. De forma semelhante, em nenhum momento os índios adotam a atitude de "pedir" mercadorias ou assistência às instituições estatais, nem fazem listas de necessidades à espera de ser satisfeitas, embora destaquem vários problemas que identificam nas suas aldeias. Como o que eles querem é reafirmar sua autonomia, estas AATI's entendem os Planos de Vida como um caminho para dar continuidade ao manejo territorial indígena que vem desde os tempos antigos. Os Planos não propõem medidas radicalmente diferentes com relação ao manejo que eles vêm dando ao entorno a través de práticas tradicionais, como a horticultura, a caça, a pesca e as trocas de vitalidade, pois, com estes Planos, os índios estão fazendo uma leitura da sua própria história e privilegiam seus sistemas de conhecimento. Na introdução do Plano de Vida, como já foi dito acima, a ACAIPI afirma: "o ordenamento territorial que estamos fazendo oferece-nos a possibilidade de entender, mostrar e levar entre nós mesmos e a outros o que significa nosso plano de vida, e, a partir daí, encontrar respostas claras com respeito ao que foi, é e será nossa forma de viver, fazendo uso dos espaços que a lei colombiana abriu" (ACAIPI 2008: 2).

Ao mesmo tempo, os Planos de Vida encarregam-se de cumprir um papel de tradução (Rappaport 2005: 94 103) que simplifica as complexidades dos sistemas de pensamento indígenas e que, em alguns aspectos, podem criar contradições e paradoxos, e certamente, erros de tradução, deliberados ou não. Por exemplo, ao descrever os terrenos salitrosos, lugares considerados como malocas dos animais onde se pode caçar somente após uma troca de vitalidade entre um kumu e o espírito dono do lugar, a ACAIPI afirma que "o xamã ou pensador, em acordo com o dono espiritual do lugar, orienta seu uso, garantindo sua sustentabilidade" (ACAIPI 2008: 8). Então, falar das relações entre os kumua e os espíitos donos como uma forma de sustentabilidade mascara a visão nativa centrada no fato de que os não humanos são pessoas com as quais se fazem trocas de vitalidade; assim, as relações geradoras de vida tornam-se preservação graças ao uso sustentável do lugar. Dessa maneira, apesar de mostrar que, por uma parte, suas relações com os seres não humanos são diferentes, os índios também podem usar uma ideia de "natureza" mais próxima da ocidental, reduzindo 
a dimensão eminentemente social que tem seu universo, uma vez que os indígenas do Pirá-paraná não têm nenhum conceito próximo ao de "natureza". Dessa perspectiva, as práticas geradoras de vida realizadas pelos kumua, como estão formuladas nas propostas, não se dirigem à manutenção das relações sociais, mas à conservação da natureza e ao desenvolvimento sustentável, que é o que os agentes estatais querem ouvir, como demonstra um dos objetivos principais do Plano de Vida: "Fortalecer nossa cultura, com base no nosso desenvolvimento individual e comunitário, como uma forma de proteger os recursos naturais e o meio ambiente e, assim, manter e melhorar nossa qualidade de vida" (ACAIPI 2008: 17). Se a isto acrescentarmos o uso essencializado que eles fazem do seu conhecimento, afirmando que cuidam da "mãe terra" para benefício de toda a humanidade, por caminhos intricados evidenciam certa “colonização da consciência" (no sentido de Comaroff e Comaroff 1991: 4) que os aproxima de um "estado natural" de suposta harmonia que os torna "guardiães ecológicos" (Cayón 2009: 216-217) e que termina por perpetuar sua posição assimétrica perante a ontologia política hegemônica do Estado: "o território é nossa origem, é o caminho por onde passa nossa história, o pensamento, a mitologia. É a mãe terra, porque dela depende todo o universo, sem ela ninguém existiria e nada poderia sobreviver. Desde a criação do mundo, os quatro seres viventes, os Ayawa, nomearam o território próprio para cada um dos grupos étnicos. Igualmente, ordenaram e deixaram regras para manejar esses territórios. Em cada território deixaram um lugar onde nasceu um grupo étnico que é como a base ou centro do mundo, é como a raiz do mundo, aquela que o sustenta, para a proteção dos seres humanos e da natureza. Todos sabemos que a ordem sempre existiu, porque o território se mantém com base nas nossas relações homens-natureza" (ACAIPI 2008: $1)$.

No entanto, se entendemos que não interessa às instituições estatais aprofundar-se nas particularidades de cada cultura e parece que estão sempre esperando dos índios certo tipo de argumentos essencializados - como o da tradição ou o de serem os "guardiães ecológicos" - que definam o que é ser indígena, como bem mostram os autores que analisam o multiculturalismo na Colômbia, ao mesmo tempo, podemos perceber que o uso de conceitos cosmológicos traduzidos, e às vezes essencializados, para um observador externo, tem um lado positivo, porque se transformam em uma ponte de inteligibilidade indispensável para negociar realidades diferentes. Por exemplo, com sua proposta, os índios opõem as leis estabelecidas pelos humanos (Constituição) àquelas feitas pelos seus demiurgos Ayawa, colocando seu ponto de partida argumentativo em um plano superior à legislação estatal. Isto está dirigido à criação de um espaço de negociação e diálogo vinculado à sua autonomia e domínio ancestral do território, pois suas práticas e conhecimentos são um legado dos demiurgos e não uma consequência dos interesses dos agentes do Estado e, com isso, tentam criar uma simetria entre ontologias. Afirmam que a "ACAIPI é a Associação de Capitães Indígenas do rio Pirá-paraná que buscam construir um caminho único que os conduza a um futuro autônomo e de convívio" (ACAIPI 2008: 1). Unindo isto ao uso de uma linguagem em que não fazem listas de demandas diretas às instituições, mas, sim, reivindicam sua forma de vida, os índios mostram a sutileza e inteligência do seu projeto a longo prazo: não estão reivindicando viver isolados ou que sejam deixados em paz para viver como seus ancestrais; o que eles demandam é ser autônomos para poder se articular à sociedade nacional. Querem saúde, escolas e projetos produtivos, mas à sua maneira. Querem decidir o rumo da sua história aproveitando as garantias que lhes oferece a legislação, eleger o que lhes parece apropriado incorporar e aprender do mundo dos brancos. E fazem isto com tanta delicadeza discursiva que 
nem as instituições estatais nem os seus agentes ou os observadores percebem as sutilezas, seja por ignorância, seja por miopia analítica.

Na hora da verdade, com conceitos como "manejo do mundo" ou “calendário ecológico cultural”, os índios do Pirá-paraná criam um espaço onde refletem, contestam e reagem à visão impositiva dos agentes e instituições estatais que têm sido forçados a aceitar. Tais conceitos exprimem bem os elementos importantes das visões nativas e são postos politicamente em ação, revelando aos agentes estatais apenas alguns aspectos superficiais do seu conhecimento. Com isto, os indígenas têm o comando sobre a quantidade de informação que é necessária e suficiente para ser entendida por seu interlocutor, ao mesmo tempo que tentam se proteger daqueles momentos em que os técnicos do Estado, aqueles agentes que, do outro lado, são interpelados cosmopoliticamente, analisam suas propostas de Planos de Vida. Assim, os índios tentam evitar que seus conhecimentos descambem, entre os agente estatais, para o limbo das crenças e superstições, quando comparados à ciência ocidental, e tentam manter a simetria entre ontologias. Os Planos de Vida buscam a inteligibilidade entre dois mundos diferentes, propõem formas de articulá-los e mostram que os índios são os únicos que se dão ao trabalho conceitual de criar caminhos de entendimento com as instituições, coisa que o aparato estatal não faz ao formular uma única legislação que cobre uma enorme diversidade cultural. Neste sentido, os indígenas praticam o método do "equívoco controlado" -no sentido de que o equívoco é o modo de comunicação por excelência entre duas perspectivas diferentes (Viveiros de castro 2004: 5)- pois constroem pontes para minimizar os equívocos característicos da comunicação interétnica e demonstram que sua concepção de política é muito mais sofisticada e polivalente, como veremos em relação ao papel central que tem o calendário ecológico na articulação da ACAIPI com outras organizações indígenas.

Desde 2005, iniciaram-se aproximações e trocas entre a ACAIPI e algumas organizações indígenas do rio Tiquié, no Brasil. Ali habitam, principalmente, membros dos povos Tuyuka, Tukano e Desana, pertencentes à família linguística Tukano oriental, como a maioria dos povos do Pirá-paraná e, no passado, havia trocas e alianças entre grupos de ambos os rios, mas os elos foram quebrados pelas ações dos missionários e seringueiros. No alto e médio rio Tiquié, há várias organizações indígenas que, desde meados da década de 1990, iniciaram um trabalho colaborativo com o Instituto Socioambiental (ISA). Estes trabalhos incluem projetos de piscicultura familiar, manejo agroecológico e fortalecimento cultural que já produziram várias publicações e materiais didáticos que serviram para que as escolas da região se tomassem espaços privilegiados para discutir o futuro e a autonomia desses povos.

As trocas e visitas entre os índios do Tiquié e do Pirá-paraná ocorreram no contexto da CANOA(Cooperaçãoe Aliança no Noroeste Amazônico), um projeto liderado pelo ISA e pela Fundação Gaia-Amazonas para contribuir com o manejo ambiental do Noroeste Amazônico. Ao promover encontros entre os líderes desses rios, propõe-se que eles façam acordos para estabelecer pautas para o manejo ritual conjunto de ambos territórios. Da perspectiva dos índios do Tiquié, os habitantes do Pirá-paranámantêm vivos vários conhecimentos e práticas rituais relativas aomanejo domundo, mas percebem que as escolas estão produzindo efeitos negativos que prejudicam a transmissão desses conhecimentos às novas gerações (Cabalzar 2006: 258), visão também partilhada pelos índios do Pirá-paraná. Para estes últimos, os problemas do Tiquié são resultado da falta de curas dos kumua e dos rituais. Então, as organizações indígenas de ambos rios decidiram colaborar para que os habitantes do Tiquié possam recuperar parte dos seus conhecimentos de manejo 
do mundo, enquanto os habitantes do Pirá-paraná almejam canalizar as boas experiências educativas do Tiquié para aplicá-las nas suas escolas.

Nesta troca, o calendário ecológico ocupa um lugar privilegiado. Depois de que os índios do Tiquié conheceram a experiência do Pirá-paraná, iniciaram um projeto de pesquisa colaborativa para elaborar seus próprios calendários ecológicos. Os grupos de pesquisadores indígenas do Tiquié são conformados por agentes indígenas de manejo ambiental, alunos da escola, professores e os conhecedores mais velhos (Cabalzar 2010: 48). Além de recompilar os conhecimentos tradicionais que têm sobre o tema, os pesquisadores indígenas dedicam-se hoje à elaboração de diários onde registram em detalhe informações sobre a sucessão dos fenômenos ecológicos, astronômicos e socioeconômicos, aspectos discutidos em oficinas e reuniões destinadas à construção de calendários ecológicos.

Porém, em si, a elaboração dos calendários ecológicos não garante a recuperação dos conhecimentos no Tiquié, embora sirva muito bem como um trabalho de referência para que, no futuro, os kumua possam adaptar seu aprendizado no Pirá-paraná às particularidades do Tiquié. Com efeito, a cosmopolítica dos indígenas de ambos os rios passa a reforçar os conhecimentos aplicados nas atividades rituais. Em troca da colaboração para fortalecer as suas escolas, os índios do Pirá-paraná deverão treinar alguns jovens do Tiquié para que aprendam as bases do conhecimento que lhes permitiria curar as estações e manejar o mundo. E esta não é uma questão menor que se resolve em poucos meses. Para poder recuperar seus conhecimentos, os índios do Tiquié precisam, entre outras coisas, resgatar suas flautas de jurupari, construir malocas, voltar a celebrar as iniciações masculinas e outros rituais, incentivar o aprendizado de alguns jovens, beber ayahuasca, reinstaurar algumas proibições alimentares e o uso de alguns lugares com nome, etc.

Aquestão não é simplesmente aplicar as curas do Pirá-paraná no Tiquié pois, como já vimos, o conhecimento de cada povo sobre seu território é específico. O que é semelhante é a estrutura do conhecimento e, por isso, ao fortalecer suas bases, pode-se acessar as especificidades em um contexto onde esses conhecimentos são complementares para um manejo mais amplo do mundo. Agora, não se pode esquecer que cada povo do Pirá-paraná é muito zeloso do seu conhecimento particular em razão das vulnerabilidades a que ficaria exposto se algum outro conhecesse seus segredos. Neste sentido, o conhecimento associado ao calendário ecológico Pirá-paraná deve criar um espaço de negociação e articulação entre os especialistas dos dois rios, uma cosmopolítica que opere na dimensão dos conhecimentos profundos e complexos aplicados pelos kumua nos rituais.

\section{CONSIDERAÇÕES FINAIS}

Apesar dos grandes problemas, a situação política atual permite a busca pela autonomia e os índios do Pirá-paraná sabem com clareza que esta só será obtida quando os agentes estatais reconhecerem e respeitarem a simetria ontológica entre mundos diversos. Para os índios, isto não é nenhuma novidade, pois seu tecido de relações políticas contempla tal simetria com outros povos vizinhos e com os seres não humanos, tendo sempre em vista uma convivência pacífica, entendida como a maneira adequada de conduzir as relações sociais com uma grande multiplicidade de seres. A incansável disposição dos índios do Pirá-paraná para ter uma convivência possível com o resto da nação colombiana, trabalhando intensamente para tornar inteligível seu mundo, de modo que sua forma de vida e seus direitos sejam respeitados, contrasta com a incompetência dos agentes e das instituições estatais para conviver com mundos diversos. 
Por isso, não se pode censurar os índios nem sua melhor capacidade de compreensão, tradução e articulação, nem sua maior inteligência no jogo das relações interétnicas porque, afinal, eles conseguiram sobreviver às diversas configurações históricas do Estado, apesar de sempre estarem em desvantagem.

É evidente que a sofisticação política dos indígenas do Pirá-paraná serve para promover ações diferenciadas segundo seus interesses e encontraram em conceitos como "calendário ecológico" e "manejo do mundo" uma forma de potencializar suas demandas e negociar diversas realidades. Quando estes conceitos operam em alianças entre diferentes organizações indígenas, servem para reconstruir parte do tecido social destruído por um contato interétnico insensato e para programar um trabalho conjunto, no futuro, para manejar o mundo. Quando atuam para reivindicar seus direitos perante as instituições estatais, os índios criam espaços para negociar sua autonomia em condições ontológicas de igualdade. Enquanto os agentes do Estado colombiano se movimentam a uma assombrosa morosidade, os índios do Pirá-paraná não se detêm esperando as respostas institucionais aos seus Planos de Vida. Por iniciativa própria, eles trabalham hoje elaborando planos de manejo ambiental para cada aldeia, tentam adequar o calendário escolar ao calendário ecológico, fazem alianças de fôlego com índios brasileiros para manejar o mundo, conseguem o reconhecimento internacional do seu sistema de conhecimentos para se proteger dos potenciais invasores do seu território e fazem rituais para dar vitalidade aos não humanos. Se isto não é sofisticação política, não imagino o que poderia ser. E isto tem o valor adicional de mostrar aos agentes estatais colombianos, na prática e permanentemente, que com a cosmopolítica indígena ambos os mundos podem e poderão conviver.

\section{AGRADECIMENTOS}

Sougratopelos fecundos comentários deAlcidaRita Ramos.Agradeçotambémos comentários deMarisol delaCadena, Jorge Legoas e dos pareceristas anônimos da revista Recherches Amérindiennes au Québec, onde originalmente foi publicado este texto.

\section{BIBLIOGRAFIA}

ACAIPI (Asociación de Capitanes Indígenas del Pirá-paraná), 2008: Plan de vida río Pirá-paraná, Gran Resguardo del Vaupés parte oriental. (Inédito).

ALBERT, Bruce, 2002: “O ouro canibal e a queda do céu. Uma crítica xamânica da economia política da natureza (Yanomami)", em Bruce Albert e Alcida Rita Ramos (orgs.), Pacificando o branco. Cosmologias do contato no norteamazônico: 239-274. Editora UNESP, São Paulo.

ÅRHEM, Kaj, 1998: 'Powers of place: territory, landscape and belonging in Northwest Amazonia”, em Nadia Lovell (org.), Local Belonging: 78-102. Routledge, London.

1981: Makuna social organization. A study in descent, alliance and the formation of corporate groups in the Northwestern Amazon. Uppsala Studies in Cultural Anthropology 4, Uppsala. 
tradiciones, relatos y saberes de la Gente de Agua. Acta Universitatis Gothenburgensis No. 17. Universidad de Gotemburgo e Instituto Colombiano de Antropología e Historia (ICANH), Bogotá.

BLASER, Mario, 2009: “The Threat of the Yrmo: the Political Ontology of a Sustainable Hunting Program”.American Anthropologist 111(1) : 10-20.

BOCAREJO, Diana, 2011: "Dos paradojas del multiculturalismo colombiano: la espacialización de la diferencia indígena y su aislamiento político". Revista Colombiana de Antropología 47(2) : 97-121.

BOCAREJO, Diana, et Eduardo Restrepo, 2011: “Introducción”. Revista Colombiana de Antropología 47(2) : 7-13.

CABALZAR, Aloísio (dir), 2010: Manejo do mundo. Conhecimentos e práticas dos povos indígenas do Rio Negro. Instituto Socioambiental, FOIRN, São Paulo.

-, 2006: “Lideranças do Tiquié estreitam laços com o Pirá-paraná, Colombia”, em Beto Ricardo e Fany Ricardo (orgs.), Povos Indígenas no Brasil 2001/2005: 257-259. Instituto Socioambiental, São Paulo.

CAYÓN, Luis, 2010: Penso, logo crio. A teoría makuna do mundo. Tese de Doutorado, Universidad de Brasília.

___-__-_, 2009: 'Descubriendo la naturaleza. Derecho Natural y Ordenamiento Territorial Indígena en la Amazonía colombiana", Anuário Antropológico 2009 (1) : 199-226.

2003: "De la guerra y los jaguares. Aproximación a las guerras interétnicas en la Amazonía", Revista de Antropología y Arqueología 14: 82-120.

2002. En las aguas de yuruparí. Chamanismo y cosmología Makuna. Ediciones Uniandes, Bogotá.

CAYÓN, Luis, et Sandra TURBAY, 2005: “Discurso chamánico, Ordenamiento Territorial y Áreas Protegidas en la Amazonía colombiana”. Journal of Latin American Anthropology 10 (1) : 88-125.

CHAVES, Margarita, 2010: 'Normative Views, Strategic Views: the Geopolitical maps in the Ethnic Territorialities of Putumayo", em Frank Hutchins e Patrick C. Wilson (orgs.), Editing Eden. A Reconsideration of Identity, Politics, and Place in Amazonia: 191-217. University of Nebraska Press, Lincoln and London.

CHAVES, Margarita, et Marta ZAMBRANO, 2006: "From blanqueamiento to reindigenización: Paradoxes of mestizaje and multiculturalism in contemporary Colombia". Revista Europea de Estudios Latinoamericanos y del Caribe $80: 5-23$.

COMAROFF, Jean et John COMAROFF, 1991: Of Revelation and Revolution: Christianity, colonialism and conciousness in South Africa. Vol. 1. University of Chicago Press, Chicago.

DESCOLA, Philippe, 2005: Par-delà nature et culture. Gallimard, Paris. 
1996: “Constructing Natures: Symbolic Ecology and Social Practice", em Philippe Descola e Gislí Pálsson (orgs.), Nature and Society: 82-102. Routledge, London.

FRANKY, Carlos, 2001: “'Ordenamiento territorial indígena amazónico: aportes desde la diversidad al Estado-Nación colombiano", em Carlos Franky e Carlos Zárate (orgs.), Imani Mundo: estudios en la Amazonía colombiana: 71-103. Universidad Nacional de Colombia, Bogotá.

GROS, Christian,2000: Políticas delaetnicidad: identidad, estadoymodernidad.:InstitutoColombianodeAntropología eHistoria, Bogotá.

JACKSON, Jean E., 1998: “Impacto de la reciente legislación nacional en la región colombiana del Vaupés", em María Lucía Sotomayor (org.), Modernidad, identidad y desarrollo: 287-314. ICAN, Colciencias, Bogotá.

JACKSON, Jean E., et María Clemencia RAMÍREZ, 2009: "Traditional, Transnational, and Cosmopolitan: the Colombian Yanacona look to the past and to the future". American Ethnologist 36(3) : 521-544.

JIMENO, Myriam, 2012: "Reforma constitucional na Colômbia e povos indígenas. Os limites da lei", em Alcida Rita Ramos (org.), Constituições Nacionais e Povos Indígenas: 53-76. Editora UFMG, Belo Horizonte.

POVINELLI, Elizabeth, 2002: The Cunning of Recognition: Indigenous Alterities and the Making of Australian Multiculturalism.: Duke University Press, London.

RAPPAPORT, Joanne, 2005: Intercultural Utopias. Public Intellectuals, Cultural Experimentation, andEthnic Pluralism in Colombia. Duke University Press, Durham and London.

RESTREPO, Eduardo, 2011: “Etnización y multiculturalismo en el bajo Atrato", Revista Colombiana de Antropología $47(2): 37-68$.

RIVERA, María Camila, et Silvia GÓMEZ, 2006: "El camino de las Entidades Territoriales Indígenas (ETI's) en la Amazonía colombiana”, em Beto Ricardo e Fany Ricardo (orgs.), Povos Indígenas no Brasil 2001/2005: 254-256. Instituto Socioambiental, São Paulo.

ROJAS, Tulio, 2002: "Plan de vida", em Margarita Rosa Serje de la Ossa, María Cristina Suaza Vargas e Roberto Pineda Camacho (orgs.), Palabras para desarmar: una aproximación crítica al vocabulario del reconocimiento cultural en Colombia: 341-350. Instituto Colombiano de Antropología e Historia, Bogotá.

STENGERS, Isabelle, 2005: “The cosmopolitical proposal”, em Bruno Latour e Peter Weibel (orgs.), Making things public: Atmospheres of democracy: 994-1003, MIT Press, Cambridge, MA.

UNESCO, s.d.: Traditional Knowledge of the Shaman Jaguars of Yuruparí. http://www.unesco.org/culture/ich/ RL/00574, (consultado no dia 23 de março de 2013).

VIECO, Juan José, 2000: “Ordenamiento territorial en el Amazonas: realidades y conflictos”, em Juan José Vieco, 
Carlos Franky e Juan Álvaro Echeverri (orgs.), Territorialidad indígena y ordenamiento en la Amazonía: 213-224. Universidad Nacional de Colombia sede Leticia, IMANI y Programa COAMA, Bogotá.

VIVEIROS DE CASTRO, Eduardo, 2004: "Perspectival Anthropology and the Method of Controlled Equivocation". Tipiti 2(1): 1-22.

-____-_-_, 2002: "Perspectivismo e multinaturalismo na América indígena”, em A inconstância da alma selvagem: 345-399. Cosac \& Naify, São Paulo.

1996: “Os pronomes cosmológicos e o perspectivismo ameríndio”. Mana 2 (2): 115-144.

WADE, Peter, 2004: “Los guardianes del poder: biodiversidad y multiculturalidad en Colombia”, em Eduardo Restrepo eAxel Rojas (orgs.), Conflicto e (in)visibilidad. Retos en los estudios de la gente negra en Colombia: 249-270. Editorial Universidad del Cauca, Popayán. 